\title{
PEMBELAJARAN PROBLEM SOLVING DISERTAI MEDIA BANGUN RUANG UNTUK MENINGKATKAN HASIL BELAJAR MATEMATIKA SISWA SMPN 1 SUKADANA
}

\author{
Ummi Rosyidah \\ Program Studi Pendidikan Matematika, Universitas Nahdlatul Ulama Lampung \\ Email: ummirosyium09@gmail.com
}

\begin{abstract}
Abstrak
Pendidikan merupakan investasi jangka panjang yang memerlukan usaha, kerjasama yang baik dari semua pihak. Namun dalam pelaksanaannya, pendidikan masih banyak mengalami permasalahan, terutama dalam proses pembelajaran. Oleh karena itu, diperlukan upaya guru untuk memilih metode yang sesuai, agar setiap materi yang disampaikaan mudah diterima dan siswa mampu belajar mandiri. Salah satu alternatif, yaitu dengan menggunakan metode pembelajaran Problem Solving disertai media bangun ruang pada materi kubus dan balok. Tujuan penelitian ini adalah adalah untuk meningkatkan hasil belajar matematika siswa melalui penggunaan metode pembelajaran problem solving disertai dengan media bangun ruang matematika siswa kelas VIII SMP Negeri 1 Sukadana. Penelitian ini menggunakan rancangan penelitian tindakan kelas. Subjek penelitian ini adalah siswa kelas VIII SMP Negeri 1 Sukadana, yang berjumlah 30 siswa. Penelitian ini terdiri dari dua siklus, data hasil belajar diperoleh melalui hasil tes pada setiap akhir siklus. Dari hasil tes, siswa yang dinyatakan tuntas dengan $\mathrm{KKM} \geq 65$ pada siklus I berjumlah 18 orang atau $60 \%$ dan pada siklus II meningkat menjadi 24 orang atau $80 \%$. Dari hasil analisis data menunjukkan bahwa penggunaan metode pembelajaran problem solving disertai dengan media bangun ruangdapat meningkatkan hasil belajar siswa pada materi kubus dan balok.
\end{abstract}

Kata Kunci: Pembelajaran Problem Solving, Hasil Belajar Matematika.

\begin{abstract}
Education is a long term investment that requires effort, cooperation from all related parties and substantial funds to achieve improvement in the educational process. Therefore, it is necessary for teachers to choose an appropriate method, so that each material received is easy to accept and students are able to learn independently. One of alternatives, namely by using the method of Problem Solving learning accompanied by geometry media on the materials of cube and cuboid. The purpose of this research is to improve students' mathematics learning outcomes through the use of problem solving learning method accompanied by mathematics geometry for students class VIII SMP Negeri 1 Sukadana. This study uses a classroom action research design. The subject of this research is 30 students of class VIII SMP Negeri 1 Sukadana. This study consists of two cycles, the learning result data obtained through the test results at each end of cycle. From the results of test, students who passed with $K K M \geq 65$ in cycle I are 18 people or $60 \%$ and in the II cycle increase to 24 people or $80 \%$. From the results of data analysis, it can be concluded the use of problem solving learning method accompanied by geometry media can improve students' learning outcomes on cube and cuboid materials.
\end{abstract}

Keywords: Problem solving learning, mathematics learning outcomes

\section{PENDAHULUAN}

Pendidikan merupakan investasi jangka panjang yang memerlukan usaha, kerjasama dari semua pihak dan juga memerlukan dana yang besar sebagai penunjang berjalannya peningkatan proses pendidikan. Upaya peningkatan sumber daya manusia ini memerlukan waktu yang panjang. Peningkatan sumber daya manusia tentunya harus melalui proses pendidikan yang baik dan terarah. Untuk itu, tugas pemerintah harus selalu berusaha meninjau dan meningkatkan mutu pendidikan yang ada di negara kita tercinta ini. Pemerintah selalu berusaha melakukan perbaikan, dan perubahan-perubahan 
terhadap sistem pendidikan. Sekolah sebagai lembaga pendidikan formal mempunyai tanggung jawab besar dalam mencapai tujuan pendidikan di sekolah.

Pada proses pembelajaran, sampai saat ini masih memberikan dominasi guru dan kurang memberikan akses bagi peserta didik untuk aktif di kelas. Siswa cenderung pasif dalam proses pembelajaran, bermalas-malasan di dalam kelas, ngantuk, berbicara dengan teman, dan siswa sulit memahami pelajaran. Hal tersebut menyebabkan hasil belajar siswa rendah dan belum mencapai ketuntasan.

Guru harus memiliki strategi dalam proses pembelajaran, agar siswa dapat belajar secara efektif dan efisien, agar tujuan yang diharapkan dapat terwujud tanpa mengabaikan keadaan siswa yang diajar baik sebagai makhluk individu maupun sebagai makhluk sosial. Salah satu langkah untuk memiliki strategi itu adalah guru harus menguasai teknik-teknik penyampaian dan penyajian materi atau yang sering disebut dengan metode mengajar. Guru harus memperhatikan kelebihan dan kelemahan metode yang digunakan sehingga dapat mendekatkan proses pembelajaran serta hasilnya pada tujuan yang diterapkan.

Mutu pendidikan dipengaruhi oleh dua faktor yaitu: faktor intern dan faktor ekstern. Faktor intern antara lain: kurikulum, media pembelajaran, metode pembelajaran, sarana dan prasarana. Sedangkan faktor ekstern antara lain: lingkungan keluarga, masyarakat, guru, dan keadaan siswa. Metode pembelajaran menjadi faktor yang penting dalam meningkatkan mutu pendidikan. Guru dituntut untuk menguasai berbagai metode mengajar, karena setiap metode memiliki kelebihan dan kelemahan serta dapat memilih metode yang tepat, sesuai dengan materi yang disajikan kepada siswa, sehingga efisien dan efektivitas pengajaran matematika dapat terwujud secara optimal termasuk terwujudnya peran siswa secara maksimal sebagai subyek belajar.

Seiring berkembangnya kehidupan manusia, matematika menjadi sangat penting dalam kehidupan manusia terlebih digunakan baik secara formal maupun non formal. Dalam pendidikan mata pelajaran matematika menjadi mata pelajaran pokok disetiap jenjang pendidikan. Matematika menjadi mata pelajaran yang penting. Tetapi pada faktanya matematika menjadi momok bagi siswa sehingga mempengaruhi hasil belajar mereka.

Berdasar hasil observasi diketahui bahwa SMP Negeri 1 Sukadana dalam meningkatkan mutu pendidikan telah melakukan berbagai upaya antara lain melengkapi buku-buku perpustakaan, mendisiplinkan proses pembelajaran baik siswa maupun guru, dan setiap guru mata pelajaran wajib membuat perangkat pembelajaran. Namun hasil belajar matematika siswa masih relatif rendah, hal tersebut dapat dilihat dari banyaknya siswa yang belum mencapai kriteria ketuntasan minimal (KKM) mata pelajaran matematika adalah 65. Berikut hasil belajar matematika siswa kelas VIII SMP Negeri 1 Sukadana:

Tabel 1. Data Nilai Hasil Belajar pada Mata Pelajaran Matematika Siswa Kelas VIII SMP Negeri 1 Sukadana

\begin{tabular}{|c|c|c|c|c|}
\hline No & Nilai & Kriteria & Jumlah & Persentase \\
\hline 1 & $\geq 65$ & Tuntas & 9 & $30 \%$ \\
\hline 2 & $<65$ & $\begin{array}{l}\text { Belum } \\
\text { Tuntas }\end{array}$ & 21 & $70 \%$ \\
\hline \multicolumn{3}{|c|}{ Jumlah } & 30 & $100 \%$ \\
\hline
\end{tabular}

Berdasarkan tabel tersebut dapat diketahui bahwa masih banyak siswa yang belum mencapai KKM. Terlihat dari 30 siswa hanya 9 siswa yang tuntas belajar atau 
sebesar $30 \%$ dan yang tidak tuntas ada 21 siswa atau $70 \%$.

Permasalahan tersebut terlihat masih kurangnya peran siswa dalam proses pembelajaran. Maka dalam hal ini, metode pembelajaran problem solving disertai media bangun ruang, dipandang penulis relevan dengan masalah di atas dalam rangka untuk meminimalisir permasalahan tersebut. Keunggulan metode pembelajaran problem solving disertai media bangun ruang adalah dapat membiasakan para siswa menghadapi, dan memecahkan masalah, karena siswa dihadapkan dengan masalah yang nyata dan relevan dalam kehidupan sehari-hari. Metode pembelajaran problem solving diharapkan dapat merangsang pengembangan kemampuan berpikir siswa, sehingga dapat meningkatkan ketuntasan belajar siswa khususnya mata pelajaran matematika.

Metode problem solving (metode pemecahan masalah) bukan hanya sekedar metode pembelajaran tetapi juga merupakan suatu metode berpikir, sebab dalam problem solving dapat menggunakan kesimpulan [1]. Hasil belajar merupakan hasil dari suatu interaksi tindak belajar dan tindak mengajar [2].

Berdasar pertimbangan inilah, maka penelitian ini dilakukan mengingat pentingnya pemilihan metode pembelajaran dalam proses pembelajaran. Maka penulis mengemukakan judul sebagai berikut: "Pembelajaran Problem Solving Disertai Media Bangun Ruang Untuk Meningkatkan Hasil Belajar Matematika Siswa SMP Negeri 1 Sukadana".

Tujuan yang ingin dicapai dalam penelitian ini adalah untuk meningkatkan hasil belajar matematika siswa melalui penggunaan metode pembelajaran problem solving disertai dengan media bangun ruang matematika siswa kelas VIII SMP Negeri 1 Sukadana.

Hipotesis pada penelitian ini adalah metode pembelajaran problem solving disertai media bangun ruang dapat meningkatkan hasil belajar matematika siswa kelas VIII SMP N 1 Sukadana.

Menurut Polya terdapat empat prinsip dalam problem solving yaitu, pertama pemahaman masalah, kedua merancang sebuah perencanan, ketiga melaksanakan rencana yang telah disusun dan keempat melihat kembali tindakan yang telah dilakukan [3].

Karwonto menjelaskan ada 5 langkah metode problem solving, yaitu: a) Ada masalah yang jelas untuk dipecahkan. Masalah ini harus tumbuh dari masalah peserta didik sesuai dengan taraf kemampuannya, b) Mencari data atau keterangan yang dapat digunakan untuk memecahkan masalah tersebut. Misalnya, dengan jalan membaca buku-buku, meneliti, bertanya dan lain-lain, c) Menetapkan jawaban sementara dari masalah tersebut. Dugaan jawaban ini tentu saja didasarkan kepada data yang telah diperoleh, pada langkah kedua di atas, d)Menguji kebenaran jawaban sementara tersebut. Dalam langkah ini peserta didik harus berusaha memecahkan masalah sehingga betul-betul yakin bahwa jawaban tersebut itu betul-betul cocok. Apakan sesuai dengan jawaban sementara atau sama sekali tidak sesuai. Untuk menguji kebenaran jawaban ini tentu saja diperlukan metode-metode lainnya seperti demonstrasi, tugas, diskusi, dan lain-lain, e) Menarik kesimpulan [1].

Saipul dan Asman menjelaskan ada 5 langkah metode Problem Solving, yaitu: a) Ada masalah yang jelas untuk dipecahkan. Masalah ini harus tumbuh dari siswa sesuai 
dengan taraf kemampuannya, b) Mencari data atau keterangan yang dapat digunakan untuk memecahkan masalah tersebut. Misalnya, dengan jalan membaca bukubuku, meneliti, bertanya, diskusi dan lainlain, c) Menetapkan jawaban sementara dari masalah tersebut. Dugaan jawaban ini tentu saja didasarkan kepada data yang telah diperoleh, pada langkah kedua diatas, d) Menguji kebenaran jawaban sementara tersebut. Dalam langkah ini siswa harus berusaha memecahkan masalah sehingga betul-betul yakin bahwa jawaban tersebut itu betul-betul cocok. Apakah sesuai dengan jawaban sementara atau sama sekali tidak sesuai. Untuk menguji kebenaran jawaban ini tentu saja diperlukan metode-metode lainnya seperti demonstrasi, tugas, diskusi, dan lain-lain, e) Menarik kesimpulan [4].

\section{METODE}

Penelitian ini dilakukan 2 siklus yang masing-masing siklus terdiri dari perencanaan, pelaksanaan, pengamatan dan refleksi. Penelitian ini dilaksanakan di SMP Negeri 1 Sukadana Kab. Lampung Timur Lampung siswa kelas VIII dengan jumlah siswa sebanyak 30 siswa yang memiliki tingkat kemampuan yang bervariasi. Dalam penelitian ini, kegiatan yang akan dilakukan adalah menilai hasil belajar siswa yang diukur dengan nilai tes. Tes dilakukan setiap akhir siklus.

Uji Instrumen yang digunakan dalam penelitian ini adalah: 1) Validasi, 2) Reliabilitas, 3) Indeks kesukaran item, 4) Daya pembeda item

\section{HASIL DAN PEMBAHASAN}

Pembelajaran siklus I dilaksanakan sebanyak 3 pertemuan, masing-masing pembelajaran dilaksanakan selama 2 jam pelajaran $(2 \times 40$ menit $)$. Berikut hasil belajar siswa pada siklus I.
Tabel 2. Hasil Belajar Siswa dalam Mengerjakan Soal pada Siklus I

\begin{tabular}{lllll}
\hline No & Nilai & Kategori & Jumlah & Persentase \\
\hline 1. & $\geq 65$ & Tuntas & 18 & $60 \%$ \\
2. & $<65$ & Belum Tuntas & 12 & $40 \%$ \\
\hline Jumlah & & 30 & $100 \%$ \\
\hline \multicolumn{5}{c}{ Sumber :Nilai Siklus I Mata Pelajaran Matematika Siswa Kelas } \\
\cline { 2 - 2 } VIIISMP Negeri 1 Sukadana.
\end{tabular}

Pembelajaran siklus II dilaksanakan sebanyak 3 pertemuan, masing-masing pembelajaran dilaksanakan selama 2 jam pelajaran $(2 \times 40$ menit). Berikut hasil belajar siswa pada siklus II.

Tabel 3. Hasil Belajar Siswa Mengerjakan Soal pada Siklus II

\begin{tabular}{ccccc}
\hline No & Nilai & Kategori & Jumlah & Persentase \\
1. & $\geq 65$ & Tuntas & 24 & $80 \%$ \\
2. & $<65$ & Belum & 6 & $20 \%$ \\
\multicolumn{4}{c}{ Tuntas } \\
\multicolumn{3}{c}{ Jumlah } & 30 & $100 \%$ \\
\hline \multicolumn{4}{c}{ Sumber :Nilai Siklus II Mata Pelajaran Matematika Siswa Kelas } \\
\multicolumn{4}{r}{ VIII SMP Negeri 1 Sukadana }
\end{tabular}

Berdasar hasil penelitian diperoleh hasil belajar matematika siswa dalam pembelajaran dengan menggunakan metode problem solving pada siklus I dan siklus II dapat dilihat pada tabel di bawah ini.

Tabel 4. Perbandingan Hasil Belajar pada Siklus I dan Siklus II

\begin{tabular}{|c|c|c|c|c|c|c|}
\hline \multirow[t]{2}{*}{ No } & \multirow[t]{2}{*}{ Kategori } & \multirow[t]{2}{*}{ Nilai } & \multicolumn{2}{|c|}{$\begin{array}{c}\text { Banyak } \\
\text { Siswa }\end{array}$} & \multicolumn{2}{|c|}{ Persentase } \\
\hline & & & $\mathrm{I}$ & II & $\mathrm{I}$ & II \\
\hline 1. & Tuntas & $\geq 65$ & 18 & 24 & $60 \%$ & $80 \%$ \\
\hline 2. & $\begin{array}{l}\text { Belum } \\
\text { Tuntas }\end{array}$ & $<65$ & 12 & 6 & $40 \%$ & $20 \%$ \\
\hline & Jumlah & & 30 & 30 & $100 \%$ & $100 \%$ \\
\hline
\end{tabular}

Berdasarkan tabel di atas terlihat ada peningkatan hasil belajar siswa yang nilainya pada kategori tuntas dari 18 siswa menjadi 24 siswa, sehingga hasil belajar pada siklus II lebih baik dari pada siklus I meskipun masih ada 6 siswa yang tidak tuntas pada siklus II, tetapi secara umum hasil belajar pada siklus II sudah 
memenuhi indikator keberhasilan yang ditetapkan. Hal ini menunjukkan bahwa pembelajaran dengan menggunakan metode problem solving terlihat meningkatkan hasil belajar siswa karena siswa terlibat aktif dalam proses pembelajaran. Selain menambah pemahaman siswa tentang materi yang dipelajari, siswa juga meningkatkan rasa percaya diri dalam mengungkapkan pendapat dalam berdiskusi bersama-sama temannya. Dalam pembelajaran dengan menggunakan metode problem solving siswa juga belajar menghargai pendapat dan hasil karya temannya serta saling bertukar pikiran dalam menyelesaikan tugas yang diberikan oleh guru.

Peningkatan hasil belajar dari siklus I ke siklus II disebabkan karena dalam pembelajaran metode problem solving ini siswa mampu memahami materi, siswa merasa senang karena dalam pembelajaran siswa diberi kesempatan ikut aktif terlibat langsung dalam menemukan penyelesaian jawaban melalui contoh-contoh konkrit yang sederhana yang sifatnya telah dipahami oleh siswa. Sehingga daya ingat siswa tentang rumus dapat bertahan lama. Selain itu, juga siswa termotivasi untuk mengembangkan kemampuannya dalam berpikir setahap demi satahap dari yang sederhana menuju pada yang lebih kompeks.

Winkel menyatakan bahwa, belajar adalah suatu aktivitas mental atau psikis yang berlangsung dalam interaksi aktif dengan lingkungan, yang menghasilkan perubahan-perubahan dalam pengetahuanpemahaman, keterampilan, dan nilai sikap. Perubahan itu bersifat secara relative konstan dan berbekas [8].

Hasil belajar siswa pada siklus I adalah rata-rata 76,25 ada di atas KKM yang ditetapkan sekolah dengan nilai 70. Hasil belajar itu berada kategori cukup baik dengan ketuntasan klasikal sebesar 65,6 \% [9]. Sedangkan hasil belajar pada siklus II sebesar 86,88 dan termasuk kategori baik dengan ketuntasan klasikal 100\%. Dengan demikian dapat disimpulkan bahwa peningkatan hasil belajar siswa dari siklus I ke siklus II dengan penggunaan metode problem solving sebesar 10,63.

Dengan adanya peningkatan hasil belajar siswa dari setiap siklus menunjukkan bahwa metode pembelajaran ini bagus untuk diterapkan dalam proses pembelajaran di sekolah. Hal tersebut sejalan dengan hasil penelitian yang menyatakan bahwa Problem solving direkomendasikan untuk digunakan dalam pembelajaran matematika [10].

\section{SIMPULAN}

Berdasarkan hasil penelitian dan pembahasan yang telah dikemukakan, maka dapat diambil kesimpulan bahwa metode pembelajaran problem solving disertai dengan media bangun ruang dapat meningkatkan hasil belajar matematika siswa kelas VIII SMP Negeri 1 Sukadana pada pokok bahasan bangun datar. Siswa yang dinyatakan tuntas dengan $\mathrm{KKM} \geq 65$ pada siklus I berjumlah 18 orang atau $60 \%$ dan pada siklus II meningkat menjadi 24 orang atau $80 \%$.

\section{DAFTAR PUSTAKA}

[1] Karwono. Strategi Pembelajaran. Metro: UM Metro Press, 2012.

[2] Dimyati. Belajar dan Pembelajaran. Jakarta: PT. Rineka Cipta, 2006.

[3] C. K. Sari, D. R. Aryuna, U. M. "The Profile o f Students' Thinking in Solving Mathematics Problems Based on Adversity Quotient. Journal of Research and Advances in Mathematics Education, vol. 1, no 36, pp. 36-48, 2016.

[4] Syaiful dan Aswan. Strategi Belajar Mengajar. Jakarta: Rineka Cipta, 2010. 
[5] P. Senapati, "Beliefs on Mathematical Problem Solving: A Case Study on Indian Under Graduate Mathematics Students". Far East Journal of Mathematical Education, vol. 11, no. 2, pp. 181203, 2013.

[6] Sanaky, H. Media Pembelajaran. Yogyakarta: Kaukaba Dipantara, 2011.

[7] P. Rowlett. Media Enhanced Teaching and Learning: case studies and evidence of effective use. MSOR Network, 2012.

[8] R. Yatim. Paradigma Baru Pembelajaran. Jakarta: Kencana Prenada Media Group, 2010.

[9] Sulastri. Penerapan Metode Problem Solving untuk Meningkatkan Aktivitas dan Hasil Belajar Siswa dalam Pembelajaran PKN di Kelas VIIIc SMP Negeri 2 Tolitoli. Jurnal Kreatif Tadulako Online, vol. 4, no. 6, pp. 313-323, 2016.

[10] J. Dindyal, "Mathematical Problem Solving for Everyone: A New Beginning". The Mathematics Educator. vol. 13, no. 2, pp. 1-20, 2012 